\title{
Article \\ From Feather to Adsorbent: Keratin Extraction, Chemical Modification, and Fe(III) Removal from Aqueous Solution
}

\author{
Sujuan Pan ${ }^{1,2, *(\mathbb{D}, \text { Changqing Wang }}{ }^{2}$, Yibo Wang ${ }^{2}$ and Rongmin Wang ${ }^{1}$ \\ 1 College of Chemistry \& Chemical Engineering, Northwest Normal University, Lanzhou 730070, China; \\ wangrm@nwnu.edu.cn \\ 2 Key Laboratory of Resource Utilization of Agricultural Solid Waste in Gansu Province, \\ Tianshui Normal University, South Xihe Road, Qinzhou District, Tianshui 741001, China; \\ wcqing2046@163.com (C.W.); wangyibo2021008@163.com (Y.W.) \\ * Correspondence: pansujuan_002@163.com; Tel.: +86-13830866425
}

check for updates

Citation: Pan, S.; Wang, C.; Wang, Y.; Wang, R. From Feather to Adsorbent: Keratin Extraction, Chemical Modification, and Fe(III) Removal from Aqueous Solution. Appl. Sci. 2021, 11, 12163. https://doi.org/ 10.3390/app112412163

Academic Editor: Zengqiang Zhang

Received: 20 October 2021

Accepted: 14 December 2021

Published: 20 December 2021

Publisher's Note: MDPI stays neutral with regard to jurisdictional claims in published maps and institutional affiliations.

Copyright: (c) 2021 by the authors. Licensee MDPI, Basel, Switzerland. This article is an open access article distributed under the terms and conditions of the Creative Commons Attribution (CC BY) license (https:// creativecommons.org/licenses/by/ $4.0 /)$.
Featured Application: This gallic acid modified feather keratin adsorbent is expected to be applied in the field of aqueous environmental remediation.

Abstract: In this work, feather keratin was extracted from the waste feather of chicken via alkyd pretreatment and reduction method, the extraction rate is above $85 \%$. The molecular weight and aggregation morphology of feather keratin in an aqueous environment were characterized by 18-angle laser light scattering gel permeation chromatography and field emission transmission electron microscopy. The relationship between the structure and properties of feather keratin is discussed. The 1-(3-dimethylaminopropyl) -3-ethylcarbondiimide hydrochloride and $N$-hydroxysuccinimide were used as activation system and cross-linkage. The gallic acid was used as modification reagent and was bonded to feather keratin chains; meanwhile, feather keratin chains were cross-linked through covalent bonds obtained the novel adsorbent (named as GA-FK gel). The GA-FK gel was investigated by IR, SEM, TGA, XRD, and BET methods. The results indicated that GA molecules successfully bonded to feather keratin chains and cross-linked between feather keratin chains. The GA-FK gel was found to have a three-dimensional network structure with abundant mesopores. Its pore size range is $1.8 \sim 90 \mathrm{~nm}$; average pore size is $19.6 \mathrm{~nm}$. Its specific surface area is $7.17 \mathrm{~m}^{2} \cdot \mathrm{g}^{-1}$. In addition, GA-FK gel was applied to remove Fe(III) in water. The maximum adsorption capacity was $319.0 \mathrm{mg} \cdot \mathrm{g}^{-1}$. The adsorption process of GA-FK gel to Fe(III) presents a typical two-stage pattern accompanied with swelling. The adsorption kinetics of GA-FK gel to Fe(III) follows the quasi-second-order model, the adsorption isotherm follows the Freundlich model. Therefore, the adsorption mechanism is non-specific adsorption.

Keywords: feather keratin; biomass; solid waste; chemical modification; adsorption property

\section{Introduction}

In recent years, with the rapid growth of the economy, a shortage of resources has gradually emerged. At the same time, it has also caused the deterioration of the global environment. To protect the environment and to promote sustainable economic and social development, the reusing of renewable biomass resources has attracted scientists' attention. The extensively studied renewable resources include biological polysaccharides such as starch, cellulose, agar, and chitin; plant proteins such as soybean protein, wheat protein, and corn protein; and other animal proteins such as casein, collagen, elastin, keratin, and silk fibroin, etc. [1]. Different from the earlier direct-use renewable resources to manufacture goods, the current researchers are devoted to developing new materials from waste biomass to achieve high-value utilization.

Worldwide, the poultry meat processing industry produces about $4.0 \times 10^{7}$ tons of feather by-products each year [2]. However, those by-products are ineffectively reused; 
only a small amount of feather was processed into low-value products such as feather powder [3] and fertilizer [4]. The most of it was discarded, possibly causing environmental pollution and even disease transmission [5]. Hence, feather as a cheap, renewable biomass resource, with a large amount of solid waste produced by poultry industry, is a potential candidate of substitute material for fossil resources.

Although research on the extraction, chemical composition, physicochemical properties of feather keratin (FK) has been conducted since the early 20th century [6,7], using discarded feather as a keratin source to develop new keratinized materials appeared only in the last twenty years [8,9]. Currently, FK can be prepared into membrane [8], hydrogel [10], fiber [11,12], biomedical materials [13,14], and daily chemical materials [15], etc. However, the modification of FK has focused on using polymer grafting or compositing [16,17], little research has been conducted using small molecules to modify FK [18]. Therefore, using small molecules to modify feather keratin has broad prospects. Gallic acid (GA, 3,5,7-trihydroxybenzoic acid) is a hydrolytic product of biological tannic acid. GA is a natural organic acid containing a phenolic ring, which has a variety of biological activities such as antibacterial and antioxidant properties [19]. It is widely used in many fields such as printing, dyeing, leather chemical industry, biomedicine, and so on. Because it has three hydroxyl groups and one carboxyl group, it was believed to be suitable for preparing functional polymer materials [20-22].

In this work, GA was employed to functionalize the FK. In the reaction, EDC-NHS was used as the mild and non-toxic activation system [23]. The GA could be bonded to FK through amide bonds. At the same time, the amide bonds between FK chains could also be formed, and the covalent disulfide bonds (-S-S-) between FK chains would be formed again. Thus, GA-modified FK gel (GA-FK gel) was prepared. The obtained GA-FK gel was characterized by IR, SEM, TGA, and XRD methods. And GA-FK gel was applied to remove the $\mathrm{Fe}(\mathrm{III})$ in aqueous solution, the adsorption properties are investigated in detail. It is expected that FK-based functional environment-friendly polymer materials will be developed, to realize the efficient recycling and high-value utilization of discarded biomass.

\section{Materials and Methods}

\subsection{Materials}

Colored chicken feather was collected from the poultry slaughter market in Feijiaying (Lanzhou, China). Urea (>98\%) was purchased from Tianjin Damao Chemical Reagent Factory. Trimethylaminomethane hydrochloride (Tris $\cdot \mathrm{HCl},>99 \%$ ), dithiothreitol (DTT, $>99 \%$ ), 1-(3-dimethylaminopropyl) -3-ethylcarbondiimide hydrochloride (EDC $\cdot \mathrm{HCl}$, Analytical Reagent (AR)), and N-hydroxysuccinimide (NHS, AR) were purchased from Gallic acid (GA, AR) and 2-morpholin ethyl sulfonic acid (MES, AR) were purchased from Saen Chemical Technology (Shanghai, China) Co., LTD. Ferric chloride hexahydrate $\left(\mathrm{FeCl}_{3} \cdot 6 \mathrm{H}_{2} \mathrm{O}, \mathrm{AR}\right)$ was purchased from Kermio Reagent Company (Tianjin, China).

\subsection{Preparation of GA-FK Gel}

Firstly, colored chicken feather was cleaned and pulverized by a small multifunctional pulverizer, the keratin was extracted by means of the reduction method that Yin et. al. [8] reported, but slightly modified. The modified step is described as the following: using $\mathrm{HCl}$ instead of ethanol to precipitate the FK, the FK sedimentation was washed with small amount of ethanol, then washed with distilled water and lyophilized. Thus, FK was obtained and ground into powder for subsequence experiments.

This method reduced the consumption of ethanol, and it is suitable to prepare the FK with a higher molecular weight because it can avoid the destruction of peptide bonds in FK molecule.

Secondly, FK was chemically modified with GA, at same time via crosslinking the amino and carboxyl groups on the molecular chain of FK to prepare the GA-FK gel. The operation was as follows: (1) Pretreatment of FK: $1 \mathrm{~g}$ FK powder was put into a $250 \mathrm{~mL}$ flask, $100 \mathrm{~mL}$ urea aqueous solution $\left(8 \mathrm{~mol} \cdot \mathrm{L}^{-1}\right)$ was added to $0.1 \mathrm{~g}$ Tris and $0.1 \mathrm{~g}$ DTT, 
$\mathrm{pH}=8$ was adjusted with $1 \mathrm{M} \mathrm{NaOH}$ solution, and at $70{ }^{\circ} \mathrm{C}$ the contents were stirred for $1 \mathrm{~h}$ under a $\mathrm{N}_{2}$ atmosphere. The obtained FK dispersive solution was dialyzed in deionized water for $24 \mathrm{~h}$ (Molecular Weight Cut Off (MwCO) of a dialysis bag is 8000 14,000 Da). Then, the dialyzed FK solution was concentrated to $1 \%(W: V)$ by ultrafiltration cup (MwCO: $5000 \mathrm{Da}$ ), obtaining the concentrated FK solution. (2) Activation of GA: $12 \mathrm{mmol}$ EDC and $6 \mathrm{mmol} \mathrm{NHS}$ were dissolved in $20 \mathrm{~mL} 0.05 \mathrm{~mol} \cdot \mathrm{L}^{-1}$ MES buffer, then $2 \mathrm{mmol} \mathrm{GA}$ was added in it, and reacted for $15 \mathrm{~min}$ at room temperature to obtain carboxy-activated GA solution (GA-NHS). (3) Modification and cross-linkage of FK: $5 \mathrm{~mL}$ activated GA solution was added to the above-concentrated FK solution (containing FK $\sim$ g) and mixed, and then reacted at $37^{\circ} \mathrm{C}$ for $24 \mathrm{~h}$. Then, the product was immersed in deionized water, washed five times to remove the free GA and other small molecule compounds, then lyophilized; the GA modified and EDC-NHS, -S-S- cross-linked FK dry gel (GA-FK gel), were obtained. The detailed experiments of extraction and preparation see the Supplementary Materials part.

\subsection{Characterization of FK}

The molecular weight of FK was characterized by GPC-RI-MALS (GPC2000, Waters, MA, USA; Optilab rEX, Wyatt, CA, USA; DAWN-EOS, Wyatt, CA, USA), and the mobile phase was $0.02 \%$ sodium azide $\left(\mathrm{NaN}_{3}\right)$ ultra-pure water solution, the flow rate was $1.000 \mathrm{~mL} \cdot \mathrm{min}^{-1}$. The aggregation morphology of FK in water was observed by TEM (Tecnai G2 F20 S-TWIN, FEI, OR, USA), the sample was prepared by the ultrasonic wet method. After dialysis, the FK solution was diluted 50 times with double steam water and dispersed by ultrasound for $30 \mathrm{~min}$. After setting for $5 \mathrm{~min}, 1$ drop was dropped onto the copper microsyn with a dropper. Then, baked for $20 \mathrm{~min}$ with an infrared lamp; the test was conducted under the $75 \mathrm{kV}$ acceleration voltage.

\subsection{Characterization of GA-FK Gel}

The chemical structure of GA-FK gel was characterized by IR (Spectrum One, Perkin Elmer, MA, USA). The sample was mixed with potassium bromide $(\mathrm{KBr})$ at a ratio of 1:100 and ground. Then, the mixture was pressed as plate for measurement. The scanning range is from 4000 to $400 \mathrm{~cm}^{-1}$. The microstructure of GA-FK gel was observed by SEM (ULTRA Plus, Zeiss, Germany), the dry sample was glued to a copper column with conductive tape, sample was sprayed gold, observed at BHT model, voltage was $5 \mathrm{kV}$. The thermal stability of GA-FK gel was measured by TGA (TG209F3, NETZSCH, Selb, Germany), testing under nitrogen $\left(\mathrm{N}_{2}\right)$ protection, the heating rate was $5^{\circ} \mathrm{C} \cdot \mathrm{min}^{-1}$, heating range was $25 \sim 800{ }^{\circ} \mathrm{C}$. The crystallinity of GA-FK gel was characterized by XRD (D/max2400, Rigaku, Japan), sample was ground into powder with a mortar. Particle size was less than 320 mesh. Powder sample was pressed into piece for analysis. Copper target, $\mathrm{K} \alpha 1$ ray $(\lambda=0.154056 \mathrm{~nm})$, voltage was $40 \mathrm{kV}$, current was $40 \mathrm{~mA}$, scanning speed was $4^{\circ} \cdot \mathrm{min}^{-1}$, scanning angle ranged from $5^{\circ}$ to $80^{\circ}(2 \theta)$. The specific surface area of GA-FK gel was determined by BET (ASAP 2020, McMuratick, GA, USA) methods, the adsorptiondesorption test of $\mathrm{N}_{2}$ was carried out at a constant temperature of $-197^{\circ} \mathrm{C}$, the equilibrium interval was $10 \mathrm{~s}$.

\subsection{Adsorption Tests of GA-FK Gel to Fe(III) in Aqueous Solution}

The adsorption experiment was carried out by batch process, the operation was as follows: $25 \mathrm{~mL} \mathrm{FeCl}_{3}$ aqueous solution was added into a $100 \mathrm{~mL}$ conical flask, the conical flask was put into the constant-temperature water bath oscillator. When the system temperature reached the set value, a certain amount of GA-FK gel was added to it. Adsorption at a set temperature was conducted for a certain time, where the rotational speed of oscillator was $120 \mathrm{r} \cdot \mathrm{min}^{-1}$. Then, the absorbance of the supernatant was measured (A) with an atomic absorption spectrophotometer. The removal rate and adsorption capacity were calculated according to the following formulae $[24,25]$ :

$$
E(\%)=\frac{C_{0}-C}{C_{0}} \times 100 \%
$$




$$
Q\left(\mathrm{mg}^{-1}\right)=\frac{\left(C_{0}-C\right) V}{m}
$$

where $C_{0}\left(\mathrm{mg} \cdot \mathrm{L}^{-1}\right)$ is the concentration of $\mathrm{Fe}(\mathrm{III})$ before adsorption; $C\left(\mathrm{mg} \cdot \mathrm{L}^{-1}\right)$ is the concentration of Fe(III) after adsorption; $V(\mathrm{~L})$ is the volume of the Fe(III) solution; and $m$ $(\mathrm{g})$ is the mass of adsorbent.

\subsection{Adsorption Kinetics and Isotherms}

Pseudo-first-order and pseudo-second-order kinetic models were used to determine the rates of adsorption of GA-FK gel to Fe(III). The sorption equilibrium was assessed using Langmuir and Freundlich adsorption isotherm models.

\section{Results}

\subsection{Preparation Mechanism of GA-FK Gel}

FK accounts for more than $90 \%$ of the total weight of feathers, and mainly exists in the $\beta$-sheet [26]. GA was used to functionalize the side groups of FK. Typical reactions are shown in Scheme 1.
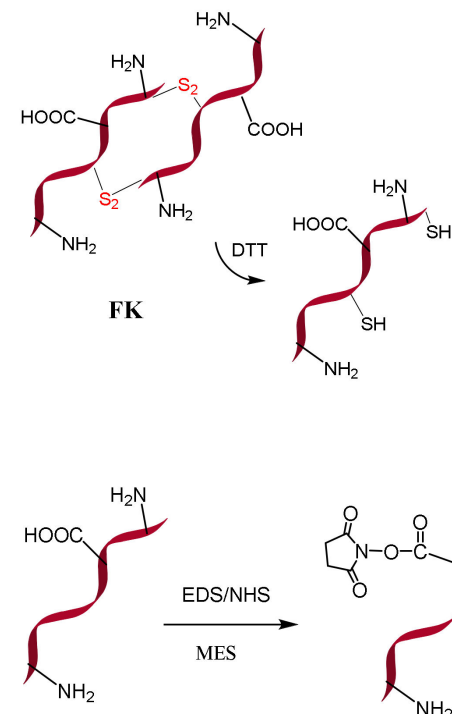
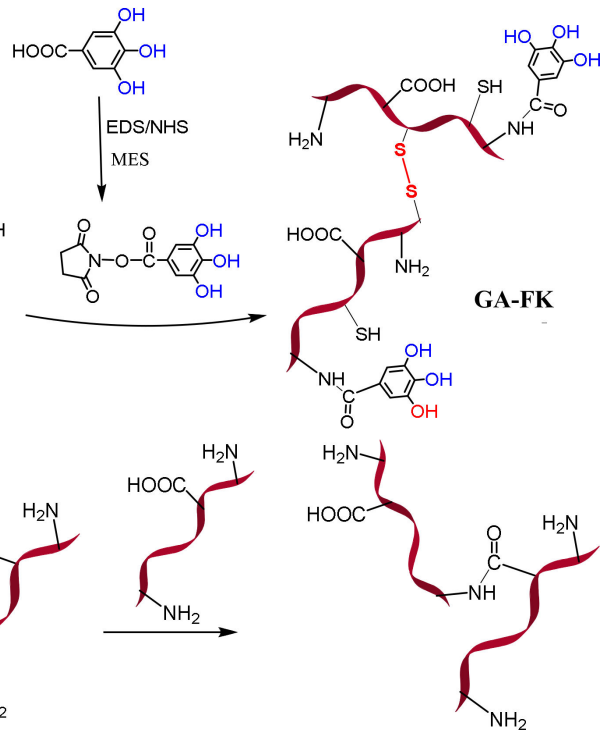

Scheme 1. The mechanism of FK bonding GA and FK chains cross-linking reaction.

In the modification reaction, the EDC-NHS activated carboxyl of GA was bonded to the amino of the FK formed amide bond, and the GA modified FK (GA-FK) was obtained. At the same time, free carboxyl groups of FK molecules were activated by excessed EDCNHS and coupled with free amino of FK molecules. Thus, between the FK chains are new covalent cross-linking together with intermolecular forces. Because chicken feather keratin is a high-sulfur macromolecule, the reduced free sulfhydryl groups can be oxidized to generate disulfide bonds (-S-S-) again. As a result, the GA-FK gel was formed. In this reaction, the GA was bonded to FK, and FK chains cross-linked by covalent bonds could change the composition and structure of FK. Consequently, we observe that GA-FK gel has have some special physical and chemical properties.

\subsection{Characterization of $F K$}

\subsubsection{Molecular Weight of FK}

GPC-RI- MALLS was used to determine the molecular weight of FK in water. The molecular weight and molecular weight distribution of FK are shown in Table 1. The result show that the average number molecular weight $(\mathrm{Mn})$ is $21,910 \mathrm{~g} \cdot \mathrm{mol}^{-1}$, it is close to $20,460 \mathrm{~g} \cdot \mathrm{mol}^{-1}$ [8], which was determined by time-of-flight mass spectrometry (TFMS) in our laboratory. Both results are different from the $10,206 \mathrm{~g} \cdot \mathrm{mol}^{-1}$ that Arai et al. re- 
ported [27], and they have verified that a single polypeptide chain B-4 in chicken feather was composed of 96 amino acid residues. Walker and Rogers's studies showed that chicken feathers are all about 100 residues in length [28,29]. Fraser and Parry found that filament of feather is assembled from dimers of FK [30], and two cysteine residues are located on the outside of the dimer and involved in inter-dimer bonding [31]. Especially in an aqueous environment, FK easily associates into a dimer due to apolar interactions and specific amino acid (cysteine residue) interactions [32]. Therefore, it can be deduced that, in fact, 21,910 is the molecular weight of FK dimer., and the molecular weight of a single polypeptide chain in extracted FK is about 10,955; there are about 103 amino acid residues.

Table 1. The molecular weight and polydispersity of feather keratin.

\begin{tabular}{cccc}
\hline & Mn (g/mol) & Mw (g/mol) & Mw/Mn \\
\hline FK & $21,910(20 \%)$ & $46,390(18 \%)$ & $2.117(27 \%)$ \\
\hline
\end{tabular}

\subsubsection{Aggregation Morphology of FK in an Aqueous Environment}

In general, the study of filamentous structures in feather in a dry state, to observe the FK molecular packing, was observed by TEM [33]. In the present study, FK molecular aggregation morphology in an aqueous environment was observed by TEM. Although it is against the TEM testing rules that samples are dry solids without water and volatile organic compounds, this result was observed by accident because the FK dispersion medium was water. The water was not completely dried under the infrared lamp during the preparation of the test sample. Hence, FK molecular aggregation morphology in an aqueous environment in different magnifications are able to be shown in Figure 1.

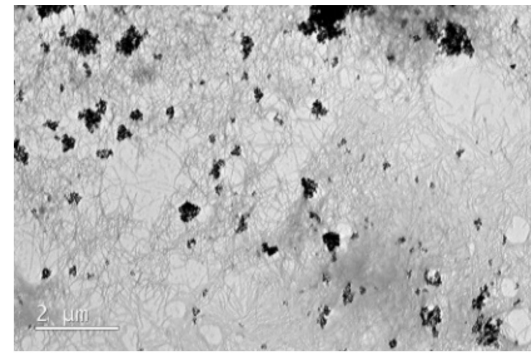

(a)

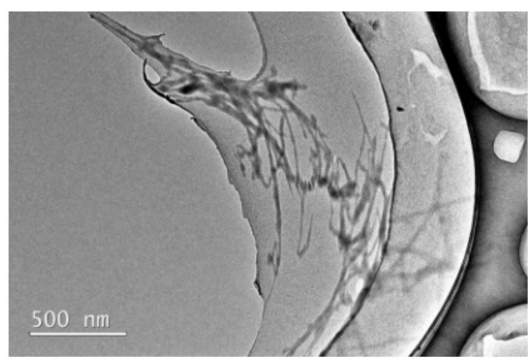

(b)

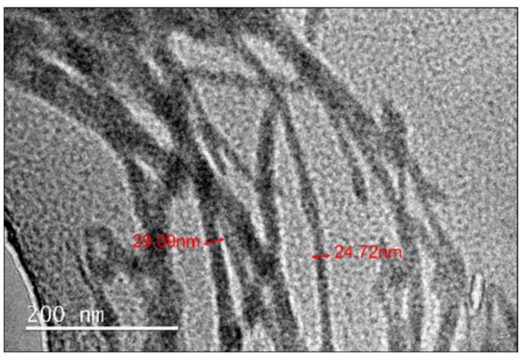

(c)

Figure 1. TEM images of FK in different magnifications: (a) low magnified; (b) middle magnified; (c) high magnified.

It can be seen in Figure 1a (low magnification) that FK molecules in water present long and straight filamentous fiber with a length far more than $2 \mu \mathrm{m}$. As can be seen from Figure $1 b$, under the radiation of a high-pressure electron beam and vacuum effect, the liquid film covering the copper mesh is quickly broken into holes due to water evaporation. As time went on, the liquid film rapidly shrunk, and fibers of FK moved with it toward the edge of the copper mesh, this made the focusing difficult. The selected region of Figure $1 \mathrm{~b}$ was enlarged as shown in Figure 1c; the diameter of the filamentous fibers thicker than $24 \mathrm{~nm}$. Because the dimers were joined up to form a continuous filament, whose diameter is about $2.4 \mathrm{~nm}$, the repeating units are stacked with a $90^{\circ}$ rotation between successive dimers [32]. Therefore, in the aqueous environment, filamentous FK fiber may be aggregated by at least ten continuous filaments. They were probably formed via Van der Waals' force, intermolecular hydrogen bonds, and salt bonds.

\subsection{Characterization of GA-FK Gel}

\subsubsection{IR Analysis}

The obtained GA-FK gel and its raw materials (FK and GA) were characterized by IR spectra, and the results are shown in Figure 2. The wide peaks at $3200 \sim 3600 \mathrm{~cm}^{-1}$ are 
attributed to the stretching vibration absorption of $\mathrm{O}-\mathrm{H}$ and $\mathrm{N}-\mathrm{H}$ in carboxyl and hydroxyl groups from FK and GA, and amino groups of FK. The strong peak near $1647 \mathrm{~cm}^{-1}$ is attributed to the amide I band of FK molecular ( $\beta$-sheet conformation); that is, the stretching vibration absorption peak of $\mathrm{C}=\mathrm{O}$ in the FK peptide bond (-CONH-). This peak remained and stronger (the shoulder peak at $1648 \mathrm{~cm}^{-1}$ ) in GA-FK gel because more amido bonds $(-\mathrm{CONH}-)$ were formed. However, it was stacked with the peak of $\mathrm{C}=\mathrm{O}$ (the sharp peak at $1623 \mathrm{~cm}^{-1}$ ) in GA which was unbonded and adsorbed by GA-FK gel. Peak at $1531 \mathrm{~cm}^{-1}$ in FK is attributed to the amide II band, the bending vibration of $\mathrm{N}-\mathrm{H}$, which is decreased in GA-FK gel. The similar phenomena are common in the literature of other small molecules modified keratin [34-36]. It may be the reason that, during the process where GA was bonded to $\mathrm{FK}$ and FK was cross-linked by EDC-NHS, $-\mathrm{NH}_{2}$ was transformed into - $\mathrm{CONH}$. It reduced the number of $\mathrm{N}-\mathrm{H}$ and restricted the bending vibration of $\mathrm{N}-\mathrm{H}$ by hydrogen bonding. The stronger absorption peak at $1369 \mathrm{~cm}^{-1}$ is attributed to $\mathrm{C}=\mathrm{C}$ stretching vibration of benzene ring of GA-FK gel. The peak at $1234 \mathrm{~cm}^{-1}$ is attributed to the amide III band that is the stretching vibration absorption peak of $\mathrm{C}-\mathrm{N}$ and in-plane flexural vibration of N-H in the FK molecule. It is reduced in the GA-FK gel, but GA-FK gel still contains the characteristic peaks of amide I, II, and III bands respectively at $1623 \mathrm{~cm}^{-1}, 1531 \mathrm{~cm}^{-1}$, and $1234 \mathrm{~cm}^{-1}$. It can be concluded that GA was bonded onto the FK chains, successfully.

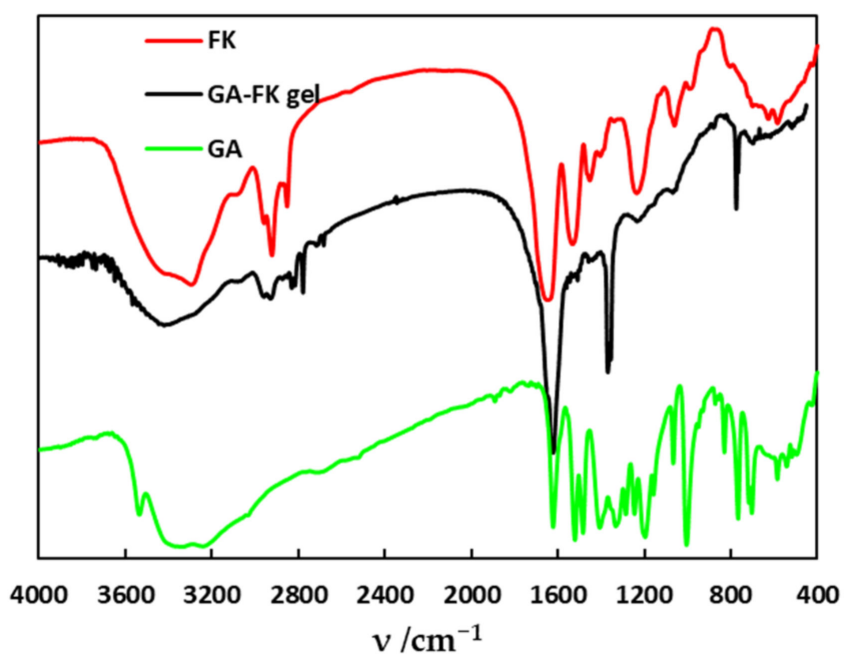

Figure 2. The IR spectra of GA-FK gel.

\subsubsection{Micro-Morphology of GA-FK Gel}

The SEM results of GA-FK gel show in Figure 3. At a magnification of $100 \mathrm{~K}$, the surface of FK is flat and shows fine cracks (see Figure 3a). It can be clearly seen that the surface of GA-FK gel is quite different from that of FK. It presents a network structure that is crisscross formed by the filaments with diameters about 40 50 nm (see Figure 3b). The results indicate that the filaments assembled the FK molecule through Van der Waals' forces, intermolecular hydrogen bonds, and salt bonds, etc. EDC-NHS cross-linked the filaments to form network structure. The fracture surface of the GA-FK gel is rough and porous (see Figure 3c). It indicates that the GA-FK gel has a three-dimensional network structure, and the flat lamellar structure was destroyed. The reason for this is that GA has a rigid benzene ring contributing to the FK molecular chains, which are difficult to get close to assemble, or even more, the new covalent bonds pull filaments away from each other. Thus, the three-dimensional network structure was formed through crosslinking in water, and the microstructure was still maintained after lyophilized, forming a plant of pores. 


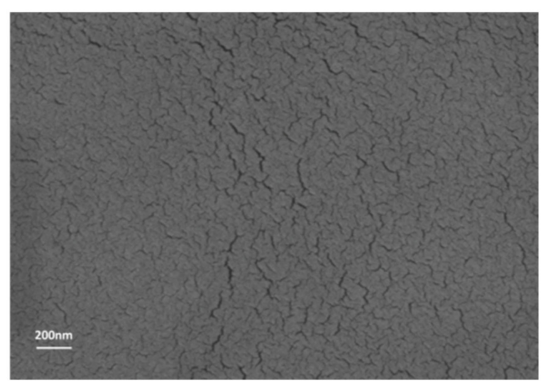

(a)

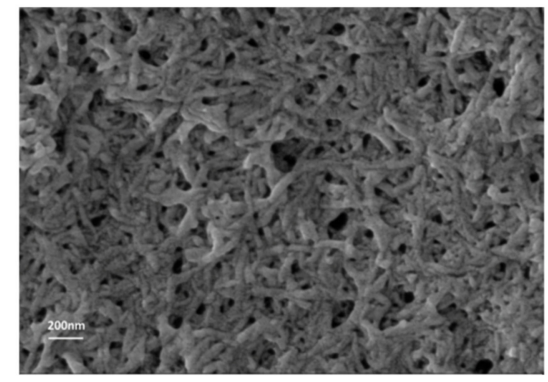

(b)

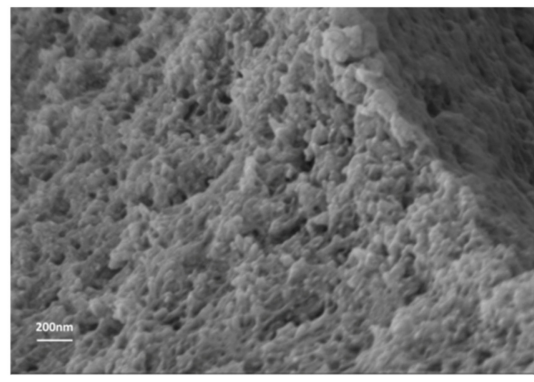

(c)

Figure 3. Micro-morphology of FK and GA-FK gel in high magnification. (a) FK; (b) GA-FK gel; (c) fracture surface of GA-FK gel.

\subsubsection{TG Analysis}

The thermogravimetric (TG) analysis of GA-FK gel and its raw materials was measured, and the results of TG and DTG curves are showed in Figure 4. It shows that GA loses adsorbed water and crystal water at $70 \sim 120{ }^{\circ} \mathrm{C}$, and starts to be sublimated at $140{ }^{\circ} \mathrm{C}$. This small molecule compound was completely sublimated below $190^{\circ} \mathrm{C}$. It has maximum weight loss rate at $167^{\circ} \mathrm{C}$. The TG curve of GA-FK gel is like FK. Compared to FK, about $3.6 \%$ of water being lost in GA-FK gel is because of the absorption of GA side groups in GA-FK. They start obvious weight loss from $220^{\circ} \mathrm{C}$. The maximum weight loss rate of GA-FK gel and FK appear at $324{ }^{\circ} \mathrm{C}$ and $310^{\circ} \mathrm{C}$, respectively. This indicates that new amido linkages formed through GA grafting and EDC-NHS cross-linking, which make the GA-FK gel more stable than that of FK. It also shows that the GA-FK gel was prepared successfully.

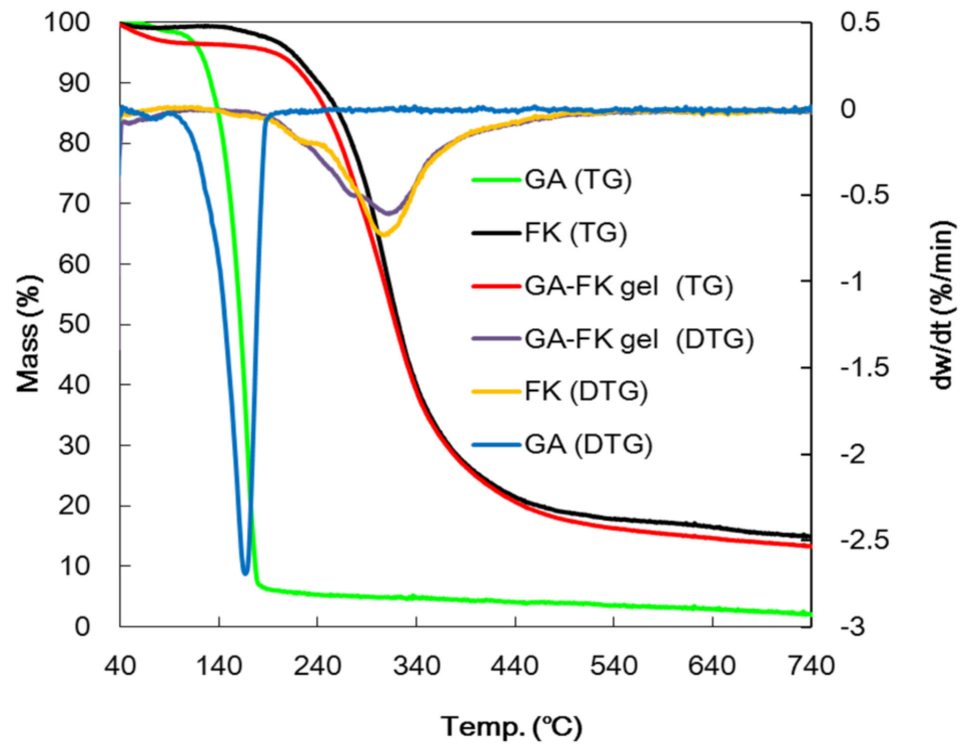

Figure 4. The TG and DTG results of GA-FK gel at $40 \sim 740{ }^{\circ} \mathrm{C}$.

\subsubsection{XRD Analysis}

The XRD results of GA-FK gel and FK are shown in Figure 5. The diffraction peaks at $2 \theta=13.7^{\circ}$ (strong, $\mathrm{d}=6.9 \AA$ ) and $19.1^{\circ}$ (weak, $\mathrm{d}=4.7 \AA$ ) are the signals of $\mathrm{FK}$, which come from $\beta$-sheets of crystallized FK. After grafting GA, the $\beta$-sheets signals in GA-FK gel are at $13.4^{\circ}(\mathrm{d}=6.9 \AA), 19.2^{\circ}(\mathrm{d}=4.7 \AA)$. The signals at $30^{\circ}$ and $41^{\circ}$ are bulging peaks of the non-crystalline region in FK and GA-FK gel, which the crystallinity of FK and GA-FK gel are $66.6 \%$ and $22.6 \%$, respectively. This indicates that the crystallization was prevented in GA-FK gel due to the bonding whit GA, and crosslinking with DEC-NHS. 


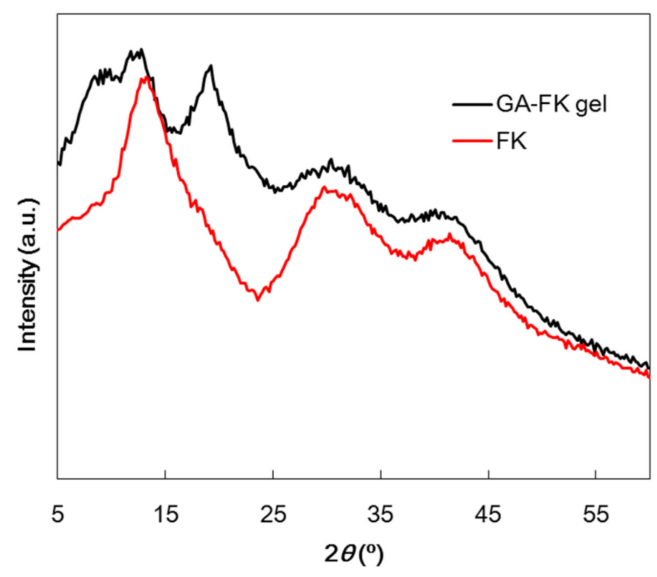

Figure 5. XRD patterns of GA-FK gel.

\subsubsection{Nitrogen Adsorption Isotherms and Pore Size Distribution}

The nitrogen adsorption-desorption isothermal and pore size distribution of GAFK gel were measured at $76 \mathrm{~K}$, the results are shown in Figure 6. It can be seen from Figure $6 \mathrm{a}$, the $\mathrm{N}_{2}$ adsorption-desorption isotherm of GA-FK gel is type-IV B isotherm (with $\mathrm{H} 2$ hysteresis ring). The adsorption capacity of GA-FK gel is $22.7 \mathrm{~cm}^{3} \cdot \mathrm{g}^{-1}$, it is bigger than that of FK $\left(12.1 \mathrm{~cm}^{3} \cdot \mathrm{g}^{-1}\right)$. The adsorption capacity rapid increases while $\mathrm{P} / \mathrm{P}_{0}>0.75$. This indicates that the adsorption is multilayer adsorption at this stage, and GA-FK gel has abundant mesoporous.

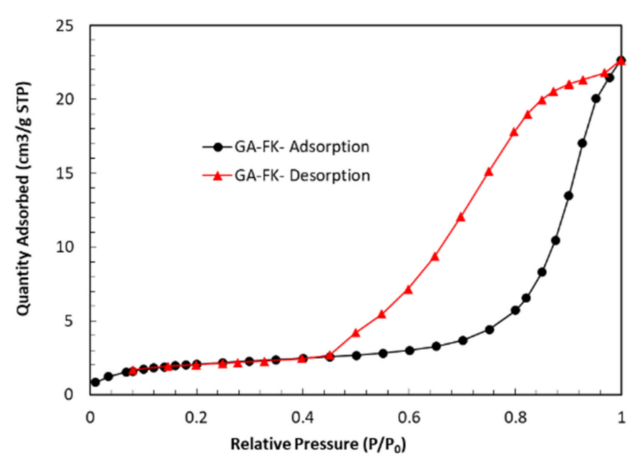

(a)

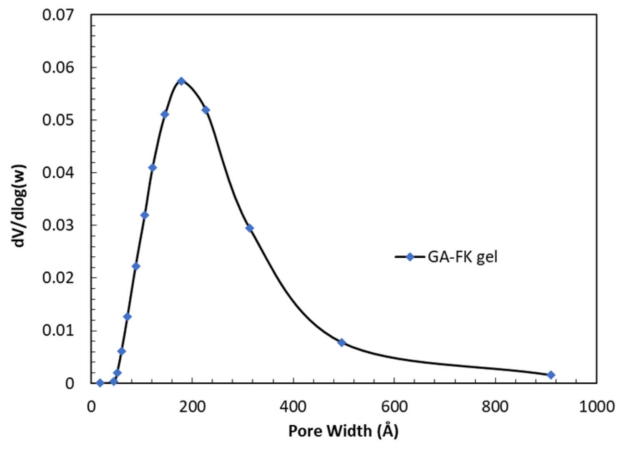

(b)

Figure 6. $\mathrm{N}_{2}$ adsorption-desorption isotherms and pore size distribution of GA-FK gel: (a) $\mathrm{N}_{2}$ adsorption-desorption isotherms; (b) pore size distribution.

The pore size distribution and specific surface area of GA-FK gel were calculated by the $\mathrm{BJH}$ method. As can be seen from Figure $6 \mathrm{~b}$, the pore size distribution of GA-FK gel is approximately symmetric and narrow. The pore size of GA-FK gel is in the range $1.8 \sim 90 \mathrm{~nm}$; with an average pore size of $19.6 \mathrm{~nm}$. The number of mesoporous $(\sim 18 \mathrm{~nm})$ accounted for the most, and the pore volume is $0.035 \mathrm{~cm}^{3} \cdot \mathrm{g}^{-1}$. The specific surface area of GA-FK gel is $7.16 \mathrm{~m}^{2} \cdot \mathrm{g}^{-1}$, it is larger than $4.11 \mathrm{~m}^{2} \cdot \mathrm{g}^{-1}$ of FK. This is because in modification reaction, EDC-NHS system activate the GA, and activated GA bonded to the amino of FK chain. Meanwhile, the EDC-NHS system activated the carboxyl on FK chain, and activated carboxyl bonded to the amino of FK chain, forming an amide bond between the inner FK molecular chains. This crosslinking led to the formation of a uniform three-dimensional network structure [22] that increased the strength of the material [20]. Moreover, based on this three-dimensional network, the GA-FK gel would be able to produce more mesopores during lyophilization.

In summary, the results of the characterization of GA-FK gel shows that the mechanical properties of FK gel were improved by bonding the rigid GA molecules and crosslinking. The GA-FK gel was homogeneous and porous, and its mesoporous number, pore volume, 
and specific surface area were significantly increased. Therefore, the preparation of GA-FK gel through this method was successful.

\subsection{Adsorption Properties of GA-FK Gel}

GA-FK gel was used as an adsorbent, and $\mathrm{Fe}(\mathrm{III})$ was used as metal pollutant model to evaluate its adsorption performance in aqueous solution. The removal efficiency was taken as the main index. The initial concentration of pollutant, the dosage of adsorbent, the adsorption temperature, and the adsorption time were investigated. The results are show in Figure 7.

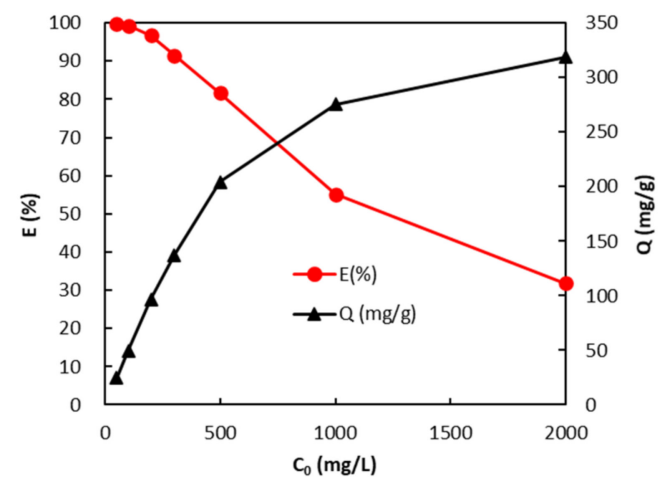

(a)

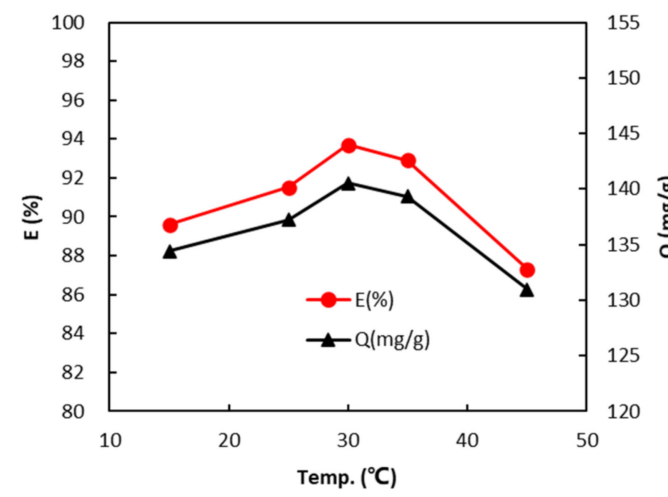

(c)

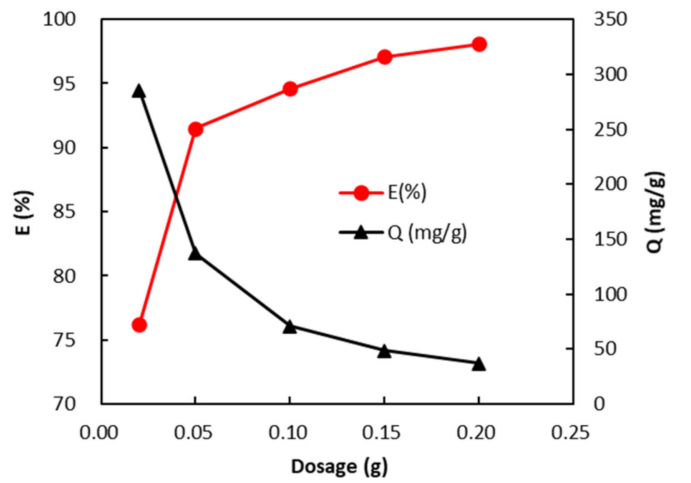

(b)

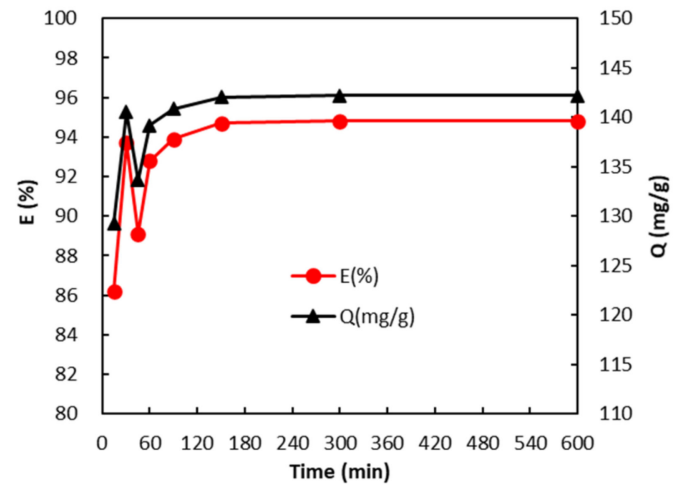

(d)

Figure 7. Adsorption performance of GA-FK gel to Fe(III) in aqueous solution $(\mathrm{pH}=6)$. (a) Effects of Fe(III) initial concentration to removal rate $\left(\mathrm{C}_{0}=50 \sim 2000 \mathrm{mg} \cdot \mathrm{L}^{-1}\right.$; Dos. $\left.=0.05 \mathrm{~g} ; 25{ }^{\circ} \mathrm{C} ; 30 \mathrm{~min}\right)$; (b) effects of adsorbent dosage to removal rate $\left(\mathrm{C}_{0}=300 \mathrm{mg} \cdot \mathrm{L}^{-1} ; \mathrm{pH}=6 ; 25^{\circ} \mathrm{C} ; 30 \mathrm{~min}\right)$; (c) effects of temperature to removal rate $\left(\mathrm{C}_{0}=300 \mathrm{mg} \cdot \mathrm{L}^{-1} ; \mathrm{pH}=6\right.$; Dos. $\left.=0.05 \mathrm{~g} ; 30 \mathrm{~min}\right)$; (d) effects of time to removal rate $\left(\mathrm{C}_{0}=300 \mathrm{mg} \cdot \mathrm{L}^{-1} ; \mathrm{pH}=6\right.$; Dos. $\left.=0.05 \mathrm{~g} ; 30^{\circ} \mathrm{C}\right)$.

With the increase in initial concentration, the Fe(III) removal rate decreased gradually (see Figure 7a). So, $300 \mathrm{mg} \cdot \mathrm{L}^{-1}$ was chosen as the initial concentration for subsequent experiments. With the increase in adsorption dosage, the Fe(III) removal rate increased but the adsorption capacity decreased (see Figure $7 \mathrm{~b}$ ). Therefore, $0.05 \mathrm{~g}$ was selected for subsequent experiments. It can be seen from Figure 7c that the Fe(III) removal rate and adsorption capacity increase first, and then decrease, with the temperature increase, and both reach the maximum value when the temperature is $30^{\circ} \mathrm{C}$. Therefore, $30^{\circ} \mathrm{C}$ is the optimum adsorption temperature.

As for adsorption time, it results in complex effects on the Fe(III) removal rate and adsorption capacity, which increases first, then decreases, and then increases again (see Figure $7 \mathrm{~d}$ ). The Fe(III) removal rate reached its first peak $(93.7 \%)$ at $30 \mathrm{~min}$. The removal rate then decreased to $89.1 \%$ at $45 \mathrm{~min}$. Then, the removal rate of $\mathrm{Fe}(\mathrm{III})$ increased gradually with the increase in adsorption time. The adsorption of Fe(III) on the GA-FK gel gradually 
reached equilibrium after $90 \mathrm{~min}$. The equilibrium adsorption capacity $\left(Q_{e}\right)$ of GA-FK gel to $\mathrm{Fe}(\mathrm{III})$ was $142.2 \mathrm{mg} \cdot \mathrm{g}^{-1}(\mathrm{E}=94.8 \%)$. Therefore, it can be concluded that the adsorption process of GA-FK gel to $\mathrm{Fe}(\mathrm{III})$ is a two-stage pattern accompanied with swelling. In the first stage, the without-swelling adsorbent (GA-FK gel) is rigid, the rapid physical adsorption is attributed to chemical-modified GA-FK gel, which has a plant of mesopores, affording it more active sites. In the second stage, the adsorbent (GA-FK gel) started swelling in the aqueous environment, it transformed from rigid to flexible. The swelling led to pores disappearing and $Q_{t}$ decreasing. When the swelling reached equilibrium, the adsorption equilibrium was reestablished. The second stage is the decisive one in all adsorption process. In this stage, the adsorption is non-specific adsorption, which includes the complexation of phenolic hydroxyl group of GA, free amino, and carboxyl of FK with Fe(III).

\subsection{Adsorption Isotherm}

In this work, the dosage of GA-FK gel was $0.05 \mathrm{~g}$, the initial concentration of Fe(III) solution was $50,100,200,300$, and $500 \mathrm{mg} \cdot \mathrm{L}^{-1}$, and the adsorption experiments were carried out at $303 \mathrm{~K}$. The experimental data were fitted and calculated by Langmuir (Formula (3) [25]) model and Freundlich (Formula (4) [25]) model, and the results are shown in Figure 8 and Table 2.

$$
\begin{aligned}
& \frac{C_{e}}{Q_{e}}=\frac{1}{K_{L} Q_{m}}+\frac{1}{Q_{m}} C_{e} \\
& \ln Q_{e}=\ln K_{F}+\frac{1}{n} \ln C_{e}
\end{aligned}
$$

where $Q_{e}$ is experimental equilibrium adsorption capacity $\left(\mathrm{mg}^{-1} \mathrm{~g}^{-1}\right) ; C_{e}$ is experimental equilibrium concentration $\left(\mathrm{mg} \cdot \mathrm{L}^{-1}\right) ; Q_{m}$ is saturated adsorption capacity $\left(\mathrm{mg} \cdot \mathrm{g}^{-1}\right) ; K_{\mathrm{L}}$ is Langmuir adsorption constant $\left(\mathrm{L} \cdot \mathrm{mg}^{-1}\right) ; K_{F}$ is Freundlich adsorption constant $\left(\mathrm{mg} \cdot \mathrm{g}^{-1}\right)$, and $1 / \mathrm{n}$ is heterogeneity parameter.

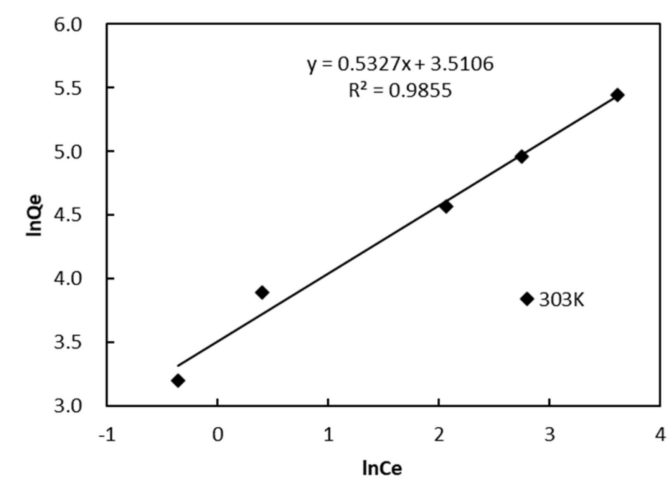

Figure 8. Adsorption isotherm of GA-FK gel to Fe(III) (Freundlich model).

Table 2. Isotherm parameters of Fe(III) adsorption by GA-FK gel.

\begin{tabular}{ccccccc}
\hline \multirow{2}{*}{$T(K)$} & \multicolumn{3}{c}{ Freundlich } & \multicolumn{4}{c}{ Langmuir } \\
\cline { 2 - 7 } & $K_{F}\left(\mathbf{L} \cdot \mathbf{m g}^{-\mathbf{1}}\right)$ & $\mathbf{1 / n}$ & $\boldsymbol{R}^{\mathbf{2}}$ & $Q_{m, c a l}\left(\mathbf{m g} \cdot \mathbf{g}^{-\mathbf{1}}\right)$ & $K_{L}\left(\mathbf{L} \cdot \mathbf{m g}^{-\mathbf{1}}\right)$ & $\boldsymbol{R}^{\mathbf{2}}$ \\
\hline 303 & 40.516 & 0.4433 & 0.9855 & 178.6 & 0.201 & 0.9253 \\
\hline
\end{tabular}

The adsorption pattern of GA-FK gel to Fe(III) is more fitting with the Freundlich model $\left(R^{2}=0.9855\right)$ (see Figure 8). Because the adsorption process of GA-FK gel to Fe(III) is a two-stage mode, in the second stage the GA-FK gel begins to swell, transforming from rigidity to flexibility until it is complete swelling. The volume of GA-FK gel particles gradually expanded, the pores disappeared, and the specific surface area changed 
dramatically. $\mathrm{Fe}$ (III) ions diffused into gel particles with the solvent. As GA bonded to FK chains, the chemical adsorption capacity was greatly improved, so the adsorption is non-specific adsorption.

It can be seen from Table 2 that the Freundlich isotherm adsorption empirical constant $K_{\mathrm{F}}$ is 40.516 . It indicates that GA-FK gel has a high adsorption affinity to $\mathrm{Fe}(\mathrm{III})$, and $0<1 / \mathrm{n}=0.4433<1$, indicating that adsorption is easy to take place. It is due to the GA molecules that it has strong complexation ability. The Langmuir isothermal adsorption empirical constant $K_{L}$ is 0.201 , and the calculated maximum adsorption capacity of GA-FK gel $\left(Q_{m, c a l}=178.6 \mathrm{mg} \cdot \mathrm{g}^{-1}\right)$ is far less than the experimental value $\left(Q_{m, \exp }=319.0 \mathrm{mg} \cdot \mathrm{g}^{-1}\right)$. It indicates that the adsorption of GA-FK gel to Fe(III) is more consistent with Freundlich model, and the adsorption is mainly non-specific adsorption.

\subsection{Adsorption Kinetics}

In this section, the dosage of GA-FK gel was $0.05 \mathrm{~g}$, the initial concentration of Fe(III) solution was $300 \mathrm{mg} \cdot \mathrm{L}^{-1}$, and the temperature was $303 \mathrm{~K}$. The experimental data were fitted and calculated using the rate equations of pseudo-first-order (Formula (5) [37]) and pseudo-second-order adsorption kinetics (Formula (6) [37]), the results are shown in Figure 9 and Table 3.

$$
\begin{gathered}
\ln \left(Q_{e}-Q_{t}\right)=\ln Q_{e}-\frac{k_{1}}{2.303} t \\
\frac{t}{Q_{t}}=\frac{1}{k_{2} Q_{e}{ }^{2}}+\frac{t}{Q_{e}}
\end{gathered}
$$

where $Q_{e}\left(\mathrm{mg} \cdot \mathrm{g}^{-1}\right)$ is the experimental value of equilibrium adsorption capacity; $Q_{t}$ $\left(\mathrm{mg} \cdot \mathrm{g}^{-1}\right)$ is the adsorption capacity at $\mathrm{t}$ time; $k_{1}\left(\mathrm{~min}^{-1}\right)$ is pseudo-first-order kinetic rate constant; $k_{2}\left(\mathrm{~g} \cdot(\mathrm{mg} \cdot \mathrm{min})^{-1}\right)$ is the pseudo-second-order rate constant; and $t(\mathrm{~min})$ is the adsorption time.

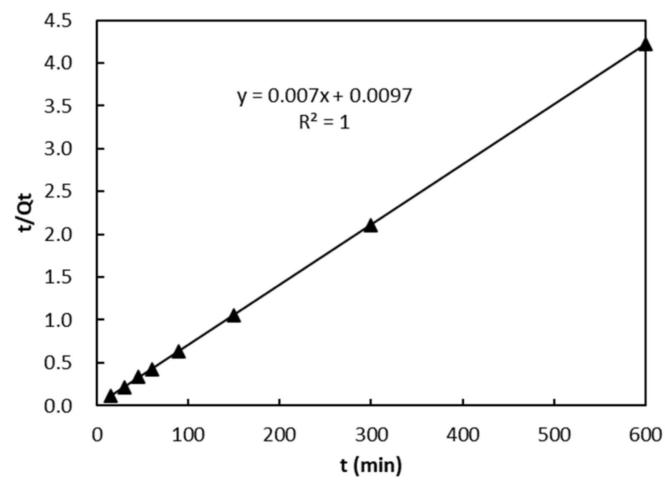

Figure 9. Adsorption kinetic fitting curves of GA-FK gel to Fe(III) (pseudo-second-order kinetic model).

Table 3. Adsorption kinetic fitting parameters of GA-FK gel to Fe(III) in different model.

\begin{tabular}{ccccccccc}
\hline \multirow{2}{*}{$T(K)$} & \multirow{2}{*}{$Q_{e, \exp }$} & \multicolumn{2}{c}{ Pseudo First Order Kinetic Model } & \multicolumn{3}{c}{ Pseudo Second Order Kinetic Model } \\
\cline { 3 - 8 } & & $k_{1}$ & $Q_{e 1, \text { cal }}$ & $\boldsymbol{R}^{\mathbf{2}}$ & $k_{2}$ & $Q_{e 2, c a l}$ & $\boldsymbol{R}^{\mathbf{2}}$ \\
\hline 303 & 142.2 & 0.155 & 38.7 & 0.8199 & 0.005 & 142.9 & 1 \\
\hline
\end{tabular}

It can be seen from Figure 9, the adsorption kinetics of GA-FK gel to Fe(III) fits well with the quasi-second-order kinetic model $\left(R^{2}=1\right)$. The calculated equilibrium adsorption quantity value $\left(Q_{e 2, c a l}=142.9 \mathrm{mg} \cdot \mathrm{g}^{-1}\right.$, calculated by the quasi-second-order kinetic equation) is remarkably close to the experimental value $\left(Q_{e, e x p}=142.2 \mathrm{mg} \cdot \mathrm{g}^{-1}\right)$ (see Table 3). Therefore, it can be concluded that the adsorption process is mainly non-specific 
adsorption. The reason is that complexation of phenolic hydroxyl group of GA, free amino and carboxyl of FK with Fe(III), GA has the strongest complexation especially.

\section{Conclusions}

The FK was extracted from waste chicken feather. Modification reagent GA was bonded onto the FK chain using the EDC-NHS activation system. Meanwhile, the FK chains were cross-linked with covalent, and the GA-FK gel was the result. This showed that the phenolic hydroxyl group had been successfully introduced to the FK chains, and gave the GA-FK gel a three-dimensional network structure, which improved the strength, toughness, and stability of FK based material. The GA-FK gel has abundant mesopores. Its pore size is in the range $1.8 \sim 90 \mathrm{~nm}$; average pore size is $19.6 \mathrm{~nm}$. Its specific surface area is $7.17 \mathrm{~m}^{2} \cdot \mathrm{g}^{-1}$. It displays a strong adsorption ability to $\mathrm{Fe}(\mathrm{III})$ in aqueous solution. The maximum capacity is $319.0 \mathrm{mg} \cdot \mathrm{g}^{-1}$. The adsorption process of GA-FK gel to Fe(III) presents a typical two-stage pattern accompanied with swelling. The adsorption kinetics of GA-FK gel to $\mathrm{Fe}(\mathrm{III})$ follows the quasi-second-order model, the adsorption isotherm follows the Freundlich model. Therefore, the adsorption mechanism is mainly non-specific adsorption, especially the complexation of phenolic hydroxyl, free amino and carboxyl of GA-FK gel with $\mathrm{Fe}(\mathrm{III})$. Although GA-FK gel is derived from solid waste, it is an environment-friendly polymer material. It is expected to be applied in the field of metal ions adsorption. Thus, it achieves the efficient recycling of waste chicken feather, and has high-value utilization.

Supplementary Materials: The following supporting information can be downloaded at: https: //www.mdpi.com/article/10.3390/app112412163/s1.

Author Contributions: Conceptualization, S.P.; methodology, S.P.; validation, R.W.; resources, R.W. and Y.W.; data curation, C.W.; writing-original draft preparation, S.P. and C.W.; supervision, Y.W.; data analysis, C.W.; investigation, S.P.; writing-review and editing, R.W. All authors have read and agreed to the published version of the manuscript.

Funding: This work was supported by the National Natural Science Foundation of China (grant number 31960268); Gansu University Industrial support and guidance projects (2019C-12); Innovation Ability Promotion Project of Colleges and Universities in Gansu province (2019A-093); Gansu Province University Innovation Fund project (2021B-204); and Key construction project of Double First-Class disciplines in Gansu Province (GSSYLXM-08).

Institutional Review Board Statement: Not applicable.

Informed Consent Statement: Not applicable.

Data Availability Statement: Not applicable.

Conflicts of Interest: The authors declare no conflict of interest.

\section{References}

1. Wang, H.-J.; Di, L.; Ren, Q.-S.; Wang, J.-Y. Applications and degradation of proteins used as tissue engineering materials. Materials 2009, 2, 613-635. [CrossRef]

2. Compassion in World Farming. Statistics: Broiler Chickens Welfare Problems; Compassion in World Farming: Surrey, UK, 2013; Volume 8, pp. 1-11.

3. Kormanjos, S.M.; Filipovic, S.S.; Radovic, V.A.; Okanovic, D.G.; Njezic, Z.B. Influence of the applied pressure of processing upon biocative comonents of diets made of feathers. Hem. Ind. 2013, 67, 135-138. [CrossRef]

4. Kucinska, J.K.; Magnucka, E.G.; Oksinska, M.P.; Pietr, S.J. Bioefficacy of hen feather keratin hydrolysate and compost on vegetable plant growth. Compost. Sci. Util. 2014, 22, 179-187. [CrossRef]

5. Franke-Whittle, I.H.; Insam, H. Treatment alternatives of slaughterhouse wastes, and their effect on the inactivation of different pathogens: A review reatment alternatives of slaughterhouse wastes, and their effect on the inactivation of different pathogens: A review. Crit. Rev. Microbiol. 2013, 39, 139-151. [CrossRef] [PubMed]

6. Speakman, J.B.; Townend, F. The titration curve of feather keratin. Trans. Faraday Soc. 1936, 32, 897. [CrossRef]

7. Lundgrcn, H.P.; Stein, A.M.; Koorn, V.M.; O'Connell, R.A. Stability of synthetic keratin fibers in alcohol-water mixtures. Theoretical basis for a new method for solubilizing feather keratin. J. Phys. Colloid Chem. 1948, 52, 180-206. [CrossRef]

8. Yin, X.-C.; Li, F.-Y.; He, Y.-F.; Wang, Y.; Wang, R.-M. Study on effective extraction of chicken feather keratins and their films for controlling drug release. Biomater. Sci. 2013, 1, 528-536. [CrossRef] 
9. $\mathrm{Xu}, \mathrm{H} . ;$ Yang, Y. Controlled de-cross-linking and disentanglement of feather keratin for fiber preparation via a novel process. ACS Sustain. Chem. Eng. 2014, 2, 1404-1410. [CrossRef]

10. Barati, D.; Kader, S.; Pajoum Shariati, S.R.; Moeinzadeh, S.; Sawyer, R.H.; Jabbari, E. Synthesis and Characterization of PhotoCross-Linkable Keratin Hydrogels for Stem Cell Encapsulation. Biomacromolecules 2017, 18, 398-412. [CrossRef] [PubMed]

11. Xu, H.; Cai, S.; Xu, L.; Yang, Y. Water-stable three-dimensional ultrafine fibrous scaffolds from keratin for cartilage tissue engineering. Langmuir 2014, 30, 8461-8470. [CrossRef]

12. Mu, B.; Hassan, F.; Yang, Y. Controlled assembly of secondary keratin structures for continuous and scalable production of tough fibers from chicken feathers. Green Chem. 2020, 22, 1726-1734. [CrossRef]

13. Shavandi, A.; Silva, T.H.; Bekhit, A.A.; Bekhit, A.E.D.A. Keratin: Dissolution, extraction and biomedical application. Biomater. Sci. 2017, 5, 1699-1735. [CrossRef] [PubMed]

14. Zarei, M.; Tanideh, N.; Zare, S.; Sari Aslani, F.; Koohi-Hosseinabadi, O.; Rowshanghias, A.; Pourjavaheri, F.; Mehryar, P.; Muthuraj, R. Electrospun poly(3-hydroxybutyrate)/chicken feather-derived keratin scaffolds: Fabrication, in vitro and in vivo biocompatibility evaluation. J. Biomater. Appl. 2020, 34, 741-752. [CrossRef] [PubMed]

15. Matyasovsky, J.; Sedliacik, J.; Matyasovsky, J., Jr.; Jurkovic, P.; Duchovic, P. Collagen and keratin colloid systems with a multifunctional effect for cosmetic and technical applications. J. Am. Leather Chem. Assoc. 2014, 109, $284-295$.

16. Wrześniewska-Tosik, K.; Marcinkowska, M.; Niekraszewicz, A.; Potocka, D.A.; Mik, T. Fibrous Composites Based on Keratin from Chicken Feathers. FIBRES Text. East. Eur. 2011, 19, 118-123.

17. Das, A.; Das, A.; Basu, A.; Datta, P.; Grupta, M.; Mukherjee, A. Newer guar gum ester/chicken feather keratin interact films for tissue engineering. Int. J. Biolog. Macromol. 2021, 180, 339-354. [CrossRef]

18. Sun, P.; Liu, Z.-T.; Liu, Z.-W. Chemically modified chicken feather as sorbent for removing toxic chromium(VI) ions. Ind. Eng. Chem. Res. 2009, 48, 6882-6889. [CrossRef]

19. Badhani, B.; Sharma, N.; Kakkar, R. RSC Advances Gallic acid: A versatile antioxidant with promising therapeutic and industrial applications. RSC Adv. 2015, 5, 27540-27557. [CrossRef]

20. Hager, A.S.; Vallons, K.J.R.; Arendt, E.K. Influence of gallic acid and tannic acid on the mechanical and barrier properties of wheat gluten films. J. Agric. Food Chem. 2012, 60, 6157-6163. [CrossRef]

21. Orliac, O.; Rouilly, A.; Silvestre, F.; Rigal, L. Effects of additives on the mechanical properties, hydrophobicity and water uptake of thermo-moulded films produced from sunflower protein isolate. Polymer 2002, 43, 5417-5425. [CrossRef]

22. Krishnamoorthy, G.; Selvakumar, R.; Sastry, T.P.; Sadulla, S.; Mandal, A.B.; Doble, M. Experimental and theoretical studies on gallic acid assisted EDC/NHS initiated crosslinked collagen scaffolds. Mater. Sci. Eng. C Mater. Biol. Appl. 2014, 43, 164-171. [CrossRef] [PubMed]

23. Yue, T.; Chien, W.; Tseng, S.-J.; Tang, S.-C. EDC/NHS-mediated heparinization of small intestinal submucosa for recombinant adeno-associated virus serotype 2 binding and transduction. Biomaterials 2007, 28, 2350-2357. [CrossRef]

24. Liu, P.; Ptacek, C.J.; Blowes, D.W.; Finfrock, Y.Z.; Liu, Y.Y. Characterization of chromium species and distribution during Cr(VI) removal by biochar using confocal micro-X-ray fluorescence redox mapping and X-ray absorption spectroscopy. Environ. Int. 2020, 134, 105216. [CrossRef]

25. Dong, N.; He, F.; Xin, J.; Wang, Q.; Lei, Z.; Su, B. A novel one-step hydrothermal method to prepare CoFe2O4/graphene-like carbons magnetic separable adsorbent. Mater. Res. Bull. 2016, 80, 186-190. [CrossRef]

26. Bragulla, H.H.; Homberger, D.G. Structure and functions of keratin proteins in simple, stratified, keratinized and cornified epithelia. J. Anat. 2009, 214, 516-559. [CrossRef]

27. Arai, K.M.; Takahashi, R.; Yokote, Y.; Akahane, K. Amino-acid sequence of feather keratin from fowl. Eur. J. Biochem. 1983, 132, 501-507. [CrossRef] [PubMed]

28. Walker, I.D.; Bridgen, J. The Keratin Chains of Avian Scale Tissue. Sequence Heterogeneity and the Number of Scale Keratin Genes. Eur. J. Biochem. 1976, 67, 283-293. [CrossRef] [PubMed]

29. Walker, I.D.; Rogers, G.E. The Structural Basis for the Heterogeneity of Chick down Feather Keratin. The Partial Amino Acid Sequence of Down Feather Kreatin. Eur. J. Biochem. 1976, 69, 341-350. [CrossRef]

30. Fraser, R.D.B.; Parry, D.A.D. The role of $\beta$-sheets in the structure and assembly of keratins. Biophys. Rev. 2009, 1, 27-35. [CrossRef] [PubMed]

31. Fraser, R.D.B.; Parry, D.A.D. Reprint of: Keratin intermediate filaments: Differences in the sequences of the Type I and Type II chains explain the origin of the stability of an enzyme-resistant four-chain fragment. J. Struct. Biol. 2014, 186, 481-490. [CrossRef] [PubMed]

32. Calvaresi, M.; Eckhart, L.; Alibardi, L. The molecular organization of the beta-sheet region in Corneous beta-proteins (betakeratins) of sauropsids explains its stability and polymerization into filaments. J. Struct. Biol. 2016, 194, 282-291. [CrossRef] [PubMed]

33. Fraser, R.D.B.; Parry, D.A.D. Molecular packing in the feather keratin filament. J. Struct. Biol. 2008, 162, 1-13. [CrossRef] [PubMed]

34. Lin, G.; Zhou, H.; Lian, J.; Chen, H.; Xu, H.; Zhou, X. Preparation of pH-responsive avermectin/feather keratin-hyaluronic acid with anti-UV and sustained-release properties. Colloids Surf. B Biointerfaces 2019, 175, 291-299. [CrossRef] [PubMed]

35. Ramakrishnan, N.; Sharma, S.; Gupta, A.; Alashwal, B.Y. Keratin based bioplastic film from chicken feathers and its characterization. Int. J. Bio. Macromol. 2018, 111, 352-358. [CrossRef] 
36. Yang, X.; Wang, X.; Yu, F.; Ma, L.; Pan, X.; Luo, G.; Lin, S.; Mo, X.; He, C.; Wang, H. Hyaluronic acid/EDC/NHS-crosslinked green electrospun silk fibroin nanofibrous scaffolds for tissue engineering. Rsc. Adv. 2016, 6, 99720-99728. [CrossRef]

37. Zou, X.; Pan, J.; Ou, H.; Wang, X.; Guan, W.; Li, C.; Yan, Y.; Duan, Y. Adsorptive removal of Cr(III) and Fe(III) from aqueous solution by chitosan/attapulgite composites: Equilibrium, thermodynamics and kinetics. Chem. Eng. J. 2011, 167, $112-121$. [CrossRef] 